\title{
Geoscięnces
}

\section{Quantificação mineralógica de bauxita boehmítica por difração de raios $X$}

\section{Mineralogical quantification of boehmitic bauxite by $X$-ray diffraction}

Guilherme Augusto Batista Soares

Mestrando, UFOP, Programa de Pós-Graduação em Engenharia Mineral

Email: guilhermepudin@uol.com.br

\section{Geraldo Magela da Costa}

Professor Associado do Departamento de Química, Universidade Federal de Ouro Preto

Email:magela@iceb.ufop.br

\section{Angela Nair Avelar}

Geóloga, Centro de Desenvolvimento Mineral DIMT - Vale

Email: angela.avelar@vale.com

\begin{abstract}
The quantitative analysis of boehmite in bauxite is of fundamental importance to determine the digestion conditions in the Bayer process. However, no method is reported in literature to perform this analysis. Hence, X-ray diffraction was used in this work to quantify boehmita, gibbsite, hematite and goethite in bauxite. A sample from Ghana containing $45 \%$ of gibbsite and $43 \%$ of boehmite was subjected to a caustic leaching at $160 \mathrm{oC}$ for the removal of gibbsite. The residue, virtually exempt of gibbsite, was treated with the dithionite-citrate-bicarbonate system for the removal of the iron oxy-hydroxides. The final product contained about $85 \%-89 \%$ of boehmite and $9 \%$ of $\mathrm{TiO}_{2}$. Calibration curves correlating the intensities of the X-ray diffraction peaks with the amounts of the mineralogical phases were obtained after mixing known quantities of gibbsite, hematite and goethite to the purified bauxite sample. Highly significant correlations were obtained for the crystallographic planes (020), (051), (002) and (251) of boehmita; (110), (200), (11-2) and (024) of gibbsite; (012), (024) and (110) of hematite; $e$ (110) and (021) of goethite. These correlations can be used to quantify the amounts of the above mentioned phases in a unknown bauxite sample.
\end{abstract}

Keywords: X-ray diffraction, boehmite, gibbsite, quantification.

\section{Resumo}

A quantificação de boehmita em bauxita é de fundamental importância para a determinação da temperatura de digestão no processo Bayer, mas não existe, na literatura, nenhum método rápido e confiável, para se realizar essa determinação. Portanto, nesse trabalho, utilizou-se a difração de raios X, para se realizar a quantificação de boehmita, gibbsita, hematita e goethita em bauxita. Uma amostra de bauxita, oriunda de Gana e contendo $45 \%$ de gibbsita e $43 \%$ de boehmita, foi submetida a uma lixiviação cáustica a $160^{\circ} \mathrm{C}$, para a remoção da gibbsita. O resíduo da lixiviação, completamente isento de gibbsita, foi tratado com o sistema ditionito-citrato-bicarbonato, para a remoção dos oxi-hidróxidos de ferro, resultando em uma amostra contendo cerca de $85 \%-89 \%$ de boehmita e $9 \%$ de $\mathrm{TiO}_{2}$. Curvas de calibração correlacionando as intensidades dos picos de difração com os teores das fases mineralógicas foram obtidas, para padrões preparados pela mistura de quantidades conhecidas de gibbsita, hematita e goethita com a amostra purificada de bauxita. Correlações significativas foram obtidas para os planos cristalográficos (020), (051), (002) e (251) da boehmita; (110), (200), (11-2) e (024) da gibbsita; (012), (024) e (110) da hematita; e (110) e (021) 
da goethita. Essas correlações podem ser utilizadas, para se quantificar o teor dessas fases em amostras semelhantes de bauxita.

Palavras-chave: Difração de raios X, boehmita, gibbsita, quantificação.

\section{Introdução}

O alumínio é o terceiro elemento mais abundante da crosta terrestre, constituindo $7,5 \%$ em massa da mesma. É um metal muito versátil e é obtido da bauxita, um minério que contém, além dos óxidos e oxi-hidróxidos de alumínio, oxi-hidróxidos de ferro, óxidos de titânio e silício, entre outros. A gibbsita é o principal componente em bauxitas tropicais, sendo formada em áreas onde há alternância de períodos quentes e chuvosos com períodos de seca. Bauxitas boehmíticas, nas quais a fase de alumínio predominante é a boehmita, são características de jazidas mais antigas, em locais de climas subtropicais, e são conhecidas também como bauxitas do mediterrâneo (Kloprogge et al., 2002). Os principais constituintes minerais, nas jazidas brasileiras, são a gibbsita $\left(\mathrm{Al}(\mathrm{OH})_{3}\right)$, goethita $(\alpha-\mathrm{FeOOH})$, hematita $\left(\alpha-\mathrm{Fe}_{2} \mathrm{O}_{3}\right)$, caulinita $\left(\mathrm{Al}_{2} \mathrm{Si}_{2} \mathrm{O}_{5}(\mathrm{OH})_{4}\right)$ e anatásio $\left(\mathrm{TiO}_{2}\right)$.

O processo Bayer consiste na digestão alcalina da bauxita em solução de hidróxido de sódio, cristalização do tri-hidróxido de alumínio, a partir de uma solução supersaturada de aluminato de sódio, $\mathrm{Na}\left[\mathrm{Al}(\mathrm{OH})_{4}\right]$ e, finalmente, a conversão térmica do trihidróxido para o óxido de alumínio anidro. A alumina é colocada em cubas eletrolíticas, gerando o alumínio primário. O rejeito é chamado lama vermelha e é descartado do processo. Se a bauxita, contém predominantemente, gibbsita e baixos teores de boehmita, a dissolução em hidróxido de sódio é feita em temperatura próxima de $150^{\circ} \mathrm{C}$. Entretanto a boehmita é muito mais resistente à dissolução, não sendo afetada no processo a baixa temperatura, requerendo uma temperatura de $250^{\circ} \mathrm{C}$ para sua dissolução. Portanto a explotação comercial, em termos de rota de processamento de uma determinada bauxita, depende da presença de boehmita e, também, da quantidade dessa fase. A mineralogia da bauxita afeta o processo de beneficiamento em três etapas do processo, sendo que, na digestão, ela afeta a solubilidade dos minerais presentes. Na precipitação, afeta a taxa de precipitação e características do trihidrato obtido e, no processo como um todo, gera a obtenção de uma alumina com parâmetros não desejados, com contaminação por outros elementos (Authier-Martin et al., 2001).

A quantificação das fases mineralógicas é parte crucial no processo de caracterização tecnológica dos minérios, contribuindo de diversas formas para a determinação da rota a ser seguida no beneficiamento, tanto dos rejeitos, como dos concentrados. Além disso, é uma ferramenta de estudo em processos de auditorias, viabilidade econômica, valor agregado e impacto ambiental na deposição do rejeito. A quantificação é passível de erros consideráveis, dependendo dos métodos utilizados, por ser potencialmente complexa. Dependendo do teor, a confirmação da presença de boehmita em bauxita é, relativamente, fácil e pode ser feita por várias técnicas analíticas, incluindo a difração de raios $\mathrm{X}$ e espectrofotometria na região do infravermelho (Wefers \& Misra, 1987). A microscopia ótica não é capaz de diferenciar a gibbsita da boehmita, devido à similaridade das propriedades óticas. Entretanto a quantificação da boehmita não é uma tarefa simples e não existe, na literatura, nenhum método estabelecido para essa finalidade, especialmente quando a mesma se encontra presente em amostras contendo gibbsita.

Para a quantificação de fases mineralógicas, utilizando a difração de raios $\mathrm{X}$, existem, basicamente, dois métodos principais, o de intensidades relativas (RIR) e o método de Rietveld (Jenkins \& Snyder 1996). O método de RIR consiste na utilização das intensidades relativas de uma determinada fase mineralógica em relação a uma outra fase padrão, quando tais métodos são difratados nas suas formas puras. $\mathrm{O}$ método de Rietveld é superior aos outros métodos de quantificação, pois utiliza os parâmetros de célula unitária das fases existentes na amostra e não aqueles fornecidos pelas substânciaspadrão (Kirwan et al. ,2009). A utilização do método de Rietveld possibili- ta a variação de inúmeros parâmetros estruturais, a fim de se conseguir o menor erro quadrado entre a diferença do difratograma observado e aquele simulado. Isso implica um ajuste no qual as estruturas referem-se àquelas presentes na amostra, considerandose, por exemplo, estresse e substituição isomórfica e não as estruturas-padrão calculadas (Jenkins \& Snyder 1996). Por esse motivo, é necessário um número de contagens elevado, para se obter uma melhor estatística dos resultados, mas, ainda, assim, os dispositivos matemáticos têm ação limitada e, frequentemente, adicionam erros aos cálculos de quantificação. É importante salientar que existem ferramentas para se eliminar a maioria dos problemas relacionados a intensificações, orientações preferenciais, estresse, microabsorções, etc. A grande diferença é que, no método de Rietveld, utiliza-se todo o difratograma, enquanto que, no método de RIR, utiliza-se, apenas, um ou mais picos selecionados.

A quantificação de uma fase mineralógica, pode também, ser realizada através da medida da intensidade de um único pico de difração. A curva de calibração é construída com a adição de quantidades conhecidas da substância de interesse, sendo esse método conhecido como método das adições (Jenkins \& Snyder 1996).

A quantificação da gibbsita em bauxita pode ser feita através da análise química, determinando-se o teor de alumínio aproveitável, ou seja, o teor de alumínio extraível a $150^{\circ} \mathrm{C}$, mas a presença de boehmita torna esse método inviável. Por outro lado, não existe um método rápido e confiável, para a quantificação de boehmita na bauxita. Sendo assim, decidiu-se investigar a utilização da difração de raios X, para fornecer informações quantitativas a respeito da mineralogia das bauxitas boehmíticas. Embora não se encontre boehmita em bauxitas brasileiras, importantes reservas desse mineral são explotadas em diversos países, tais como Guiné e Grécia (Bardossy \& Aleva 1990). 


\section{Materiais e métodos}

Devido à inexistência de um padrão comercial de boehmita, optou-se, pela purificação de uma bauxita oriunda de Gana contendo, inicialmente cerca de $43 \%$ de boehmita e $45 \%$ de gibbsita (amostra BauGana1). A remo-

\section{Dugestão cáustica}

A digestão cáustica, para a remoção da gibbsita da amostra BauGana1, foi realizada em uma autoclave com volume total de 3 litros, com uma rampa de aquecimento de

\section{Remoção de óxidos de ferro}

Cerca de 0,5 g da amostra BauGana2 foram tratadas com $25 \mathrm{ml}$ de uma solução de citrato-bicarbonato (1-0,3 $\mathrm{mol} / \mathrm{l}$ respectivamente)

\section{Curva de calibração}

À amostra de bauxita purificada (BauGana3), contendo, essencialmente, boehmita e $\mathrm{TiO}_{2}$, adicionaram-se quantidades apropriadas de uma gibbsita comercial, de modo a se obterem padrões com proporções variadas dessas duas fases aluminosas. Silício metálico (100 $\mathrm{mg}$ ) foi adicionado como padrão interno a $500 \mathrm{mg}$ de todas as composições. Quatro padrões contendo hematita comercial e goethita sintética também foram preparados. As composições de todos os padrões estão listadas na Tabela 1. ção da gibbsita foi feita através da digestão Bayer, enquanto que os óxidos de ferro foram removidos tratando-se a amostra com o sistema ditionito-citrato-bicarbonato (Mehra \& Jackson 1960). Tentativas de se removerem o

$1,33^{\circ} \mathrm{C} / \mathrm{min}$. A temperatura máxima atingida foi de $169^{\circ} \mathrm{C}$ (pressão de 95 PSI). Após a estabilização a $160^{\circ} \mathrm{C}$ (pressão de 77 PSI), a digestão foi mantida por uma hora. A massa de rutilo e o anatásio por separação com di-iodometano $(\mathrm{d}=3,3 \mathrm{~g} / \mathrm{mL})$ se mostraram ineficazes, possivelmente devido ao intercrescimento dos cristais de boehmita com os cristais de anatásio e rutilo (Zwingmann et al., 2009).

bauxita foi de $100 \mathrm{~g}$ e a de soda foi de 56,61 g/L de água destilada. Após a digestão, o sólido resultante foi filtrado a, aproximadamente, $90^{\circ} \mathrm{C}$ (amostra BauGana2).

a $80^{\circ} \mathrm{C}$. Após 30 minutos, adicionaram-se três porções de um grama de ditionito em intervalos de $15 \mathrm{mi}$ nutos o qual foi deixado e deixou-se sob aquecimento por uma hora. O resíduo foi centrifugado, lavado com água destilada e seco em estufa a $80^{\circ} \mathrm{C}$ (amostra BauGana3).
As análises químicas da bauxita original e das duas amostras purificadas foram feitas através de espectrometria de emissão atômica por plasma no equipamento Varian Vista Pro. As amostras foram fundidas com uma mistura de $\mathrm{Na}_{2} \mathrm{CO}_{3}$ e $\mathrm{Na}_{2} \mathrm{~B}_{4} \mathrm{O}_{7}$ e dissolvidas com $\mathrm{HCl}$ diluído.

Os difratogramas de raios $\mathrm{X}$ foram obtidos em um aparelho Shimadzu XRD 6000 equipado com tubo de Fe e um monocromador de grafite. As varreduras foram feitas entre $5-125^{\circ}$ (2-theta) com velocidade do goniômetro de $0,5^{\circ}$ por minuto. A identificação das fases mineralógicas e as determinações das áreas e intensidades dos picos foram feitas com o programa Jade. Os picos foram ajustados com uma função Pseudo-Voigt após subtração do background e do K $\alpha 2$.

As análises termogravimétricas (TGA) foram realizadas em um aparelho Du Pont SDT2960 entre a temperatura ambiente e $1000^{\circ} \mathrm{C}$ com taxa de aquecimento de $10^{\circ} \mathrm{C} / \mathrm{min}$. em atmosfera de ar sintético com fluxo de $100 \mathrm{~mL} / \mathrm{min}$.

\begin{tabular}{lccccccc}
\hline Padrão & Boehmita & Gibbsita & $\mathrm{TiO}_{2}$ & Hematita & Goethita & Silício & Total \\
\hline Padrão1 & 70,8 & 0,00 & 7,5 & 0,0 & 0,0 & 16,7 & 95,0 \\
Padrão2 & 63,8 & 8,3 & 6,7 & 0,0 & 0,0 & 16,7 & 95,5 \\
Padrão3 & 56,7 & 16,7 & 6,0 & 0,0 & 0,0 & 16,7 & 96,1 \\
Padrão4 & 49,6 & 25,0 & 5,2 & 0,0 & 0,0 & 16,7 & 96,5 \\
Padrão5 & 42,5 & 33,3 & 4,5 & 0,0 & 0,0 & 16,7 & 97,0 \\
Padrão6 & 35,4 & 41,7 & 3,8 & 0,0 & 0,0 & 16,7 & 97,6 \\
Padrão7 & 28,3 & 50,0 & 3,0 & 0,0 & 0,0 & 16,7 & 98,0 \\
Padrão8 & 21,3 & 58,3 & 2,3 & 0,0 & 0,0 & 16,7 & 98,6 \\
Padrão9 & 14,2 & 66,7 & 1,5 & 0,0 & 0,0 & 16,7 & 99,1 \\
Padrão10 & 7,1 & 75,0 & 0,8 & 0,0 & 0,0 & 16,7 & 99,6 \\
Padrão11 & 0,0 & 83,3 & 0,0 & 0,0 & 0,0 & 16,7 & 100,0 \\
Padrão12 & 56,7 & 8,3 & 6,0 & 4,2 & 4,2 & 16,7 & 96,1 \\
Padrão13 & 47,2 & 6,9 & 5,0 & 12,5 & 8,3 & 16,7 & 96,6 \\
Padrão14 & 37,8 & 5,6 & 4,0 & 20,8 & 12,5 & 16,7 & 97,4 \\
Padrão15 & 28,3 & 4,2 & 3,0 & 29,2 & 16,7 & 16,7 & 98,1 \\
\hline
\end{tabular}

Tabela 1

Composição (\% p/p) dos padrões utilizados na construção das curvas de calibração. 


\section{Resultados e discussões}

Os resultados das análises químicas da bauxita inicial BauGana1 estão listados na Tabela 2 e o difratograma de raios $\mathrm{X}$ está apresentado na Figura 1. A mineralogia dessa amostra consiste de $43 \%$ de boehmita, $45 \%$ de gibbsita, $1 \%$ de hematita, $2 \%$ de goethita e $4 \%$ de anatásio e rutilo. Após a digestão cáustica, não se observou a presença de gibbsita (Figura 1b). Três extrações sucessivas com o sistema ditionito-citrato-bicarbonato (amostra BauGana3) aparentemente foram suficientes para a remoção da hematita e goethita, conforme mostra o difratograma da Figura 1c. Entretanto os resultados das análises químicas (Tabela 2) mostram a presença de cerca de $2 \%$ de ferro após as extrações, demonstrando,

Tabela 2 Análises químicas (\% p/p) da amostra de bauxita original (BauGana1) e após extração de gibbsita (BauGana2) e dos óxidos de ferro (BauGana3).

Figura 1

Difratogramas de raios $X$ da bauxita original (BauGana1) e após extração de gibbsita (BauGana2) e dos óxidos de ferro (BauGana3). Boehmita: B; gibbsita: Gb; goethita: Gt; hematita: $\mathrm{H}$; rutilo: R; anatásio: An. nesse caso, a incapacidade da difração de raios X de detectar esse teor. A amostra BauGana3 contém 85\% de boehmita, $2 \%$ de goethita e $9 \%$ de anatásio e rutilo. $\mathrm{Na}$ curva da análise termogravimétrica dessa amostra, observou-se uma perda de massa de cerca de $1 \%$, relativa à umidade, e uma outra perda de 15,0\%, em aproximadamente, $500^{\circ} \mathrm{C}$. Essa perda se refere à desidratação da boehmita, resultando em alumina como produto. $\mathrm{O}$ teor de boehmita calculado a partir da perda de massa acima mencionada fornece um teor de 98,5\%. Obviamente esse valor está incorreto, visto existirem cerca de $11 \%$ de impurezas, conforme os dados da Tabela 2. Com base no teor de $\mathrm{Al}_{2} \mathrm{O}_{3}($ Tabela 2), calcula-se que o teor de boehmita é de $81,2 \%$. Por outro lado, existem cerca de $11 \%$ de impurezas, o que resulta em um fechamento químico de $\sim 93 \%$. Os dados experimentais não sugerem a existência de nenhuma outra fase mineralógica nessa amostra. Desta forma, acredita-se que o teor de alumínio mostrado na Tabela 2 está subestimado, talvez devido a erros inerentes ao método de quantificação. O teor de boehmita calculado por diferença é de 89\%. Dessa forma, para efeito de cálculos com as curvas de calibração, admitiu-se a concentração de $85 \%$ de boehmita nesta amostra. Esse valor é uma média entre a concentração calculada por diferença na análise química e aquela calculada pela concentração de $\mathrm{Al}_{2} \mathrm{O}_{3}$.

\begin{tabular}{lcccccc}
\hline Amostra & $\mathrm{Al}_{2} \mathrm{O}_{3}$ & $\mathrm{Fe}_{2} \mathrm{O}_{3}$ & $\mathrm{SiO}_{2}$ & $\mathrm{TiO}_{2}$ & PF & Total \\
\hline BauGana1 & 65,1 & 2,8 & 0,7 & 4,2 & 25,6 & 98,4 \\
BauGana2 & 66,9 & 5,1 & 0,5 & 8,6 & 14,9 & 96,0 \\
BauGana3 & 69,0 & 1,9 & 0,5 & 9,0 & 15,5 & 95,9 \\
\hline
\end{tabular}

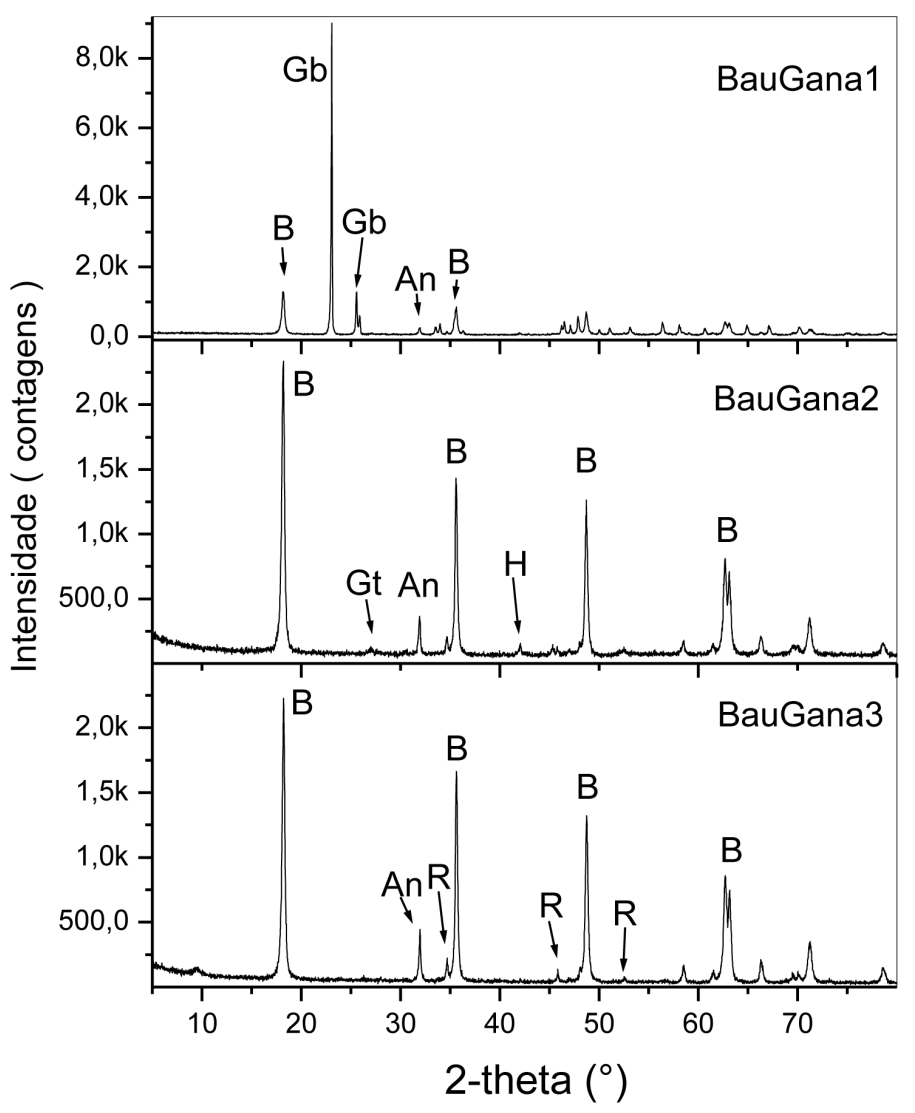

As intensidades absolutas e integradas dos principais picos de difração da boehmita, gibbsita, hematita, goe-

thita, anatásio e rutilo foram determinadas para cada um dos padrões listados na Tabela 1. Os difratogramas de quatro desses padrões estão apresentados na Figura 2.

As correlações entre as intensida- 
des dos picos de difração e as quantidades de cada uma das fases presentes nos padrões listados na Tabela 1 foram investigadas e, como esperado, para muitos picos de cada fase mineralógica não se obtiveram correlações satisfatórias, certamente devido a efeitos de orientação preferencial. Entretanto, alguns picos apresentaram excelentes correlações entre as intensidades (e áreas) e as concentrações das fases, conforme pode ser verificado nos exemplos da Figura 3. Correlações acima de 0,98 foram obtidas para os seguintes planos cristalográficos:

- boehmita: (020), (051), (002) e (251);

- gibbsita: (110), (200), (11-2) e (024);

- hematita: (012), (024) e (110);

- goethita: (110) e (021)

Para o rutilo e anatásio, os únicos picos que apresentaram uma correlação satisfatória $\left(\mathrm{r}^{2}=0,87\right)$ foram o (110) e o (101), respectivamente.

Para se verificar a aplicabilidade das correlações, calcularam-se os teores de boehmita e de gibbsita, na amostra BauGana1. As quantidades de boehmita calculadas usando a intensidade e a área do pico (051) foram de $44 \%$ e $45 \%$, respectivamente, em boa concordância com o valor experimen-

\begin{tabular}{lcccccc}
\hline Amostra & $\mathrm{Al}_{2} \mathrm{O}_{3}$ & $\mathrm{Fe}_{2} \mathrm{O}_{3}$ & $\mathrm{SiO}_{2}$ & $\mathrm{TiO}_{2}$ & $\mathrm{PF}$ & Total \\
\hline BauGana1 & 65,1 & 2,8 & 0,7 & 4,2 & 25,6 & 98,4 \\
BauGana2 & 66,9 & 5,1 & 0,5 & 8,6 & 14,9 & 96,0 \\
BauGana3 & 69,0 & 1,9 & 0,5 & 9,0 & 15,5 & 95,9 \\
\hline
\end{tabular}

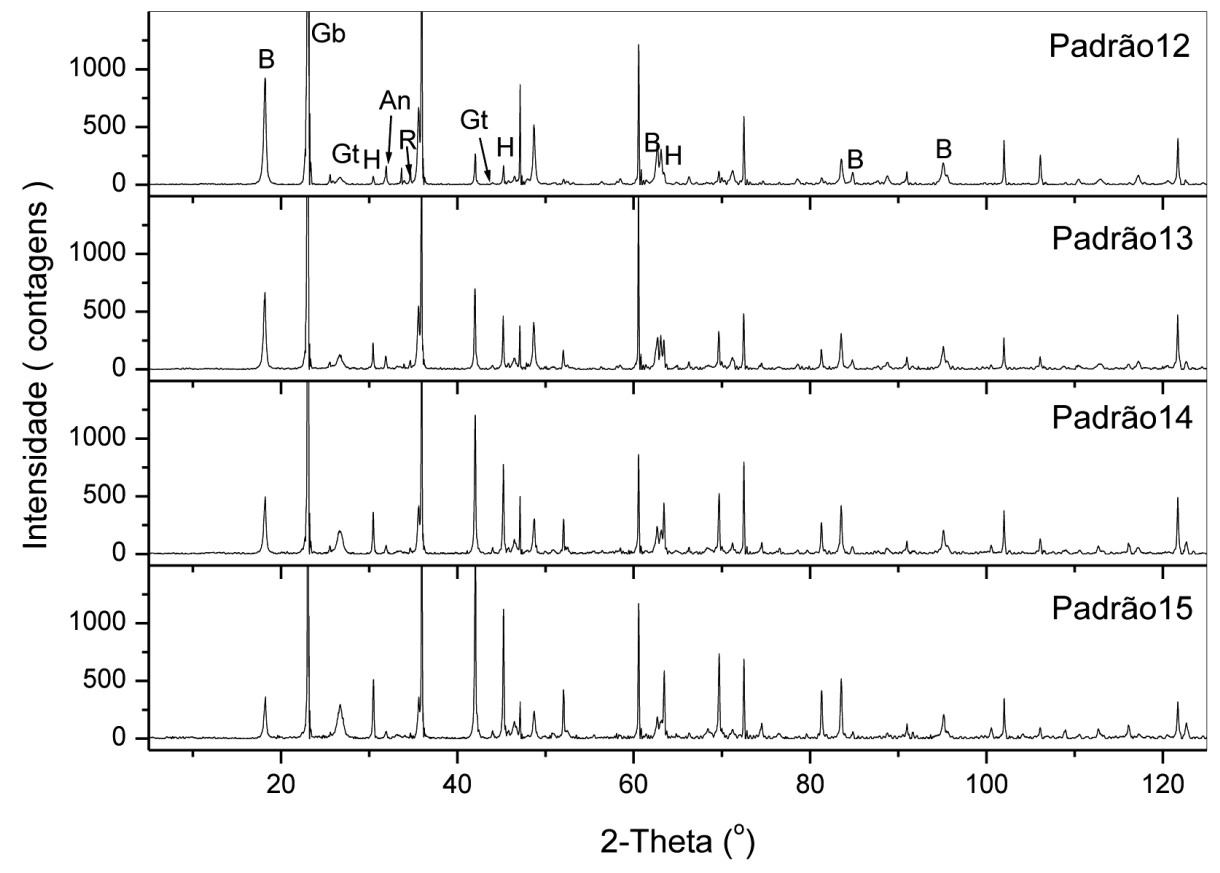

\section{Conclusão}

As curvas de calibração lineares que correlacionam as quantidades de gibbsita, boehmita, hematita, goethita, anatásio e rutilo com as intensidades de alguns picos de difração de raios X selecionados dessas fases possibilitam a quantificação dessas fases em amostras de bauxita que possuam mineralogias similares. $\mathrm{O}$ uso dos picos selecionados elimina os erros de tal. Por outro lado, para a gibbsita, os valores calculados, usando os quatro picos acima mencionados, foram muito discrepantes entre si $195 \%, 94 \%, 66 \%$ e $54 \%$ ) e em relação ao valor experimental $(45 \%)$. O fato se terem obtido boas correlações lineares para a gibbsita, mas que não são utilizáveis para a estimativa do teor nessa amostra natural, provavelmente se deve à utilização de gibbsita sintética na construção das curvas de calibração. Apesar dessa limitação, o teor de gibbsita pode ser calculado a partir do teor de boehmita e do teor de alumínio total obtido por análise química.

\section{Tabela 2}

Análises químicas (\% p/p) da amostra de bauxita original (BauGana1) e após extração de gibbsita (BauGana2) e dos óxidos de ferro (BauGana3).

Figura 2

Difratogramas de raios $X$ de alguns padrões contendo diferentes proporções de boehmita (B); gibbsita (Gb); goethita $(\mathrm{Gt})$; hematita $(\mathrm{H})$; rutilo $(\mathrm{R})$; anatásio (An).

\section{Agradecimentos}

orientação preferencial, permitindo a quantificação dos minerais, mesmo aqueles que se apresentam na forma de polimorfos, caso do rutilo e do anatásio. 
Figura 3

Correlação entre a concentração da fase e a intensidade do pico de difração relativo ao plano (051) da boehmita, (11-2) da gibbsita, (101) do anatásio, (110) do rutilo,

(110) da hematita e (110) da goethita.

\section{Referências Bibliográficas}
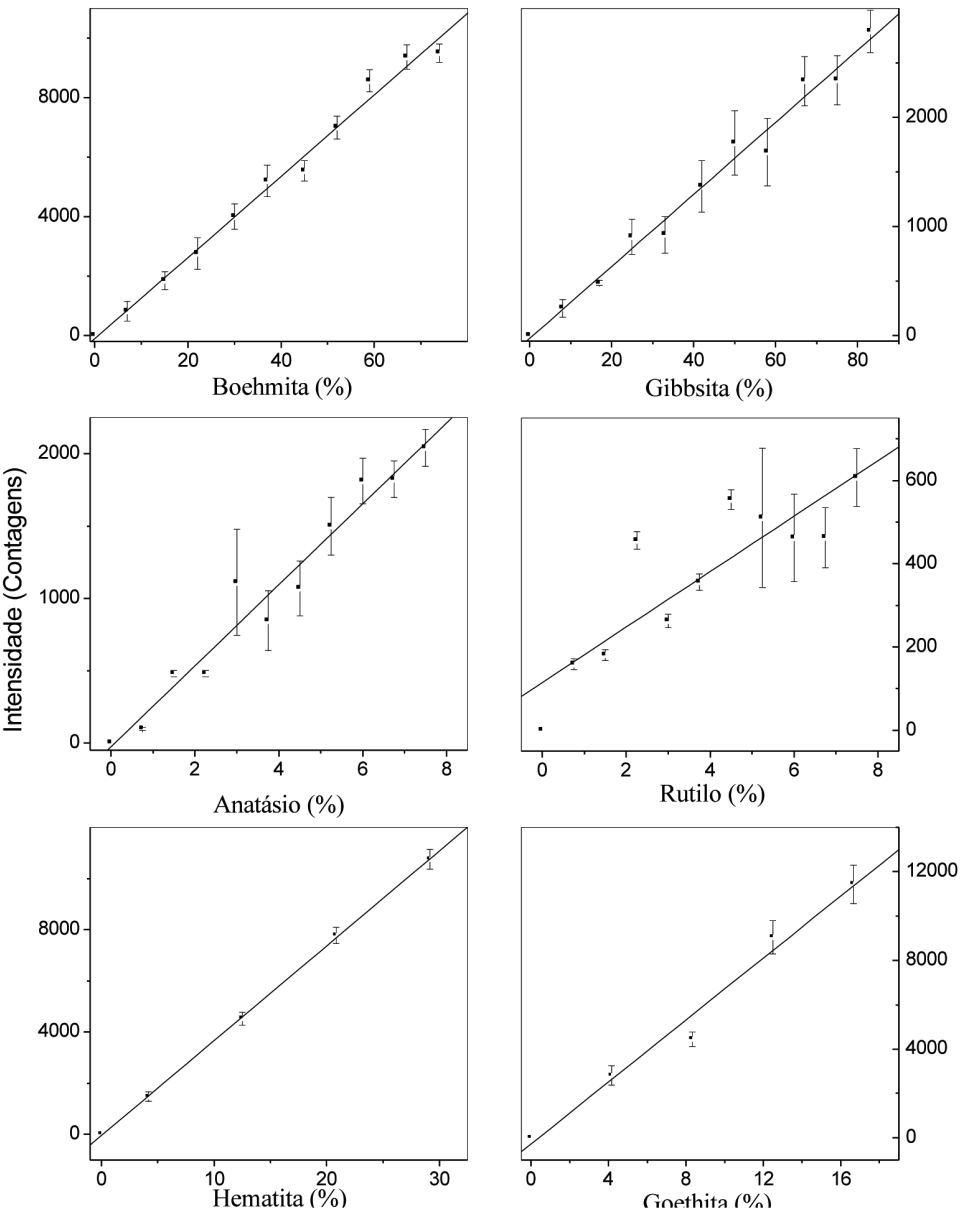

AUTHIER-MARTIN, M., FORTÉ, G., OSTAP, S.,SEE, J. The mineralogy of Bauxite for producing smelter-grade alumina. Journal of mineralogy overview, v. 53, n. 12, p. 36-40. 2001.

BARDOSSY, G. E ALEVA, G., J., J. Lateritic bauxites. Developments in Economic Geology, Elsevier, Amsterdam, 27, 1990. 624 p.

KLOPROGGE, J. T.; RUAN, H. D.; FROST, R. L. Thermal Decomposition of bauxites minerals: infrared emission spectroscopy of gibbsite, boehmite and diaspore, Journal of Material Science, n. 37, p. 1121-1129. 2002.

JENKINS, R.; SNYDER, R. L. 1996. Introduction to X-ray Powder Diffractometry, John Wiley \& Sons, INC., New York. 1992. p. 355-387.

KIRWAN, L. J.; DEENEY, F. A.; CROKE, G. M.; HODNETT, K. 2009. Characterization of various Jamaican bauxites ores by quantitative Rietveld X-ray powder diffraction and 57Fe Mössbauer spectroscopy, International Journal of Mineral Processing, 91: 14-18

MEHRA, O. P.; JACKSON, M. L. 1960. Iron oxide removal from soils and clays by a dithionite-citrate system buffered with sodium bicarbonate, Seventh National Conference on Clays and Clay Minerals, 317-327.

WEFERS, K.; MISRA, C. 1987. Oxides and Hydroxides of Aluminum, Alcoa Laboratories, Pittsburgh. Pgs 92.

ZWINGMANN, N.; JONES, A. J.; DYE, S.; SWASH, P. M.; GILKES, R. J. 2009. A method to concentrate boehmita in bauxite by dissolution of gibbsite. Hydrometallurgy, v.97, p. 80-85,2009

Artigo recebido em 24 de maio de 2010. Aprovado em 05 de fevereiro 2014. 